\title{
Hyponatremia in Association With Second-Generation Antipsychotics: A Systematic Review of Case Reports
}

\author{
Sarah Naz Ali, MPH, ${ }^{1}$ Lydia A. Bazzano, MD, PhD ${ }^{1,2,3}$ \\ ${ }^{1}$ Department of Epidemiology, Tulane University School of Public Health and Tropical Medicine, New Orleans, LA ${ }^{2}$ Department of Internal \\ Medicine, Ochsner Clinic Foundation, New Orleans, LA ${ }^{3}$ The University of Queensland School of Medicine, Ochsner Clinical School, \\ New Orleans, LA
}

\begin{abstract}
Background: Hyponatremia is generally defined as a serum sodium level $<135 \mathrm{mmol} / \mathrm{L}$ and is considered severe if serum sodium is $<125 \mathrm{mmol} / \mathrm{L}$. Hyponatremia is a potentially life-threatening medical comorbidity for patients with schizophrenia. The incidence of hyponatremia in patients with schizophrenia who are taking second-generation antipsychotics (SGAs) has not been well established.

Methods: We conducted a systematic review of case reports of hyponatremia associated with the use of SGAs in patients with schizophrenia. We searched MEDLINE (from 1946 through September 2016) using the medical subject headings antipsychotic agents, hyponatremia, and water intoxication to identify reported diagnoses of hyponatremia following treatment with SGAs in patients with schizophrenia.

Results: We abstracted 12 potentially relevant case reports from 157 records. Nine case reports met the selection criteria. Three cases involved the use of aripiprazole (Abilify), 3 involved the use of risperidone (Risperdal), and the other 3 cases involved ziprasidone, olanzapine, and clozapine. Approximately equal numbers of males and females were represented, and 2 of the 9 patients were aged $\geq 60$ years. The average patient age was 47 years, and the average time to the hyponatremia event was 17 days. The average serum sodium was $138 \mathrm{mmol} / \mathrm{L}$ at baseline, $112 \mathrm{mmol} / \mathrm{L}$ at treatment nadir, and $138 \mathrm{mmol} / \mathrm{L}$ after treatment discontinuation.

Conclusion: Hyponatremia can result from the use of SGAs in patients with schizophrenia and can be avoided with proper management of treatment. Physicians, psychiatrists, and other healthcare workers should be aware of the potential for severe hyponatremia with the use of commonly prescribed SGAs. SGA-induced hyponatremia is generally reversible after discontinuing treatment.
\end{abstract}

Keywords: Antipsychotic agents, aripiprazole, hyponatremia, risperidone

Address correspondence to Lydia A. Bazzano, MD, PhD, Department of Internal Medicine, Ochsner Clinic Foundation, 1401 Jefferson Hwy., New Orleans, LA 70121. Tel: (504) 842-4747. Email: Ibazzano@ochsner.org

\section{INTRODUCTION}

Schizophrenia is a chronic debilitating psychiatric illness occurring in approximately $1 \%$ of the world's population. ${ }^{1}$ Hyponatremia affects $4 \%$ of patients with schizophrenia, ${ }^{2,3}$ even without the use of antipsychotic medications, and occurs in $10 \%$ of patients with chronic schizophrenia who take antipsychotic medications. ${ }^{4}$ The use of antipsychotic medications may put patients with schizophrenia at an increased risk of developing hyponatremia., ${ }^{2,4}$ The occurrence of hyponatremia among patients with schizophrenia who are taking second-generation antipsychotics (SGAs) in the clinical setting has not been well established and warrants further research.

Hyponatremia is generally defined as a serum sodium level $<135 \mathrm{mmol} / \mathrm{L}$. ${ }^{5} \mathrm{~A}$ serum sodium level $<125 \mathrm{mmol} / \mathrm{L}$ is considered severe hyponatremia and can have irreversible clinical consequences such as coma, death, rhabdomyolysis, and neurologic damage. ${ }^{4,6,7}$ In a study of 7,113 psychiatric inpatients, 347 (4.9\%) patients had hyponatremia, with $29 \%$ of patients experiencing mild symptoms. Mild symptoms included gait impairment (including falls) in $45 \%$ of patients, confusion in $30 \%$, sedation in $26 \%$, and dyspepsia in $41 \% .^{8}$ In severe cases (a serum sodium level $<125 \mathrm{mmol} / \mathrm{L}$ ), salt wasting can occur, leading to symptoms such as headache, agitation, mental confusion, delirium, convulsions, coma, and encephalopathy. ${ }^{2,9}$ Hyponatremia most frequently occurs in hospitalized patients and is prevalent in females and the elderly population who may be vulnerable to severe complications. ${ }^{6,7}$

Patients with schizophrenia are more commonly treated with SGAs than with first-generation antipsychotics (FGAs). ${ }^{10}$ An estimated 670,000 of 2 million adult patients prescribed 
Table 1. Antipsychotic Medications

\begin{tabular}{lcc}
\hline $\begin{array}{l}\text { Monotherapy } \\
\text { First-Generation } \\
\text { Antipsychotic Medications }\end{array}$ & $\begin{array}{c}\text { Monotherapy } \\
\text { Second-Generation } \\
\text { Antipsychotic Medications }\end{array}$ & $\begin{array}{c}\text { Combination Therapy } \\
\text { Second-Generation } \\
\text { Antipsychotic Medications }\end{array}$ \\
\hline Chlorpromazine (Thorazine) & Aripiprazole (Abilify) & Olanzapine + fluoxetine (Symbyax) \\
Droperidol (Inapsine) & Asenapine (Saphris) \\
Fluphenazine (Prolixin) & Clozapine (Clozaril) \\
Haloperidol (Haldol) & lloperidone (Fanapt) \\
Loxapine (Loxitane) & Lurasidone (Latuda) \\
Perphenazine (Trilafon) & Olanzapine (Zyprexa) \\
Pimozide (Orap) & Paliperidone (Invega) \\
Prochlorperazine (Compro) & Quetiapine (Seroquel) \\
Thioridazine (Mellaril) & Risperidone (Risperdal) \\
Thiothixene (Navane) & Ziprasidone (Geodon) \\
Trifluoperazine (Stelazine) & \\
\hline
\end{tabular}

an antipsychotic medication in the United States (according to findings from the 2004-2005 US Medical Expenditure Panel Survey) are prescribed SGAs for the treatment of psychiatric symptoms. Table 1 presents a list of FGAs and SGAs. ${ }^{10}$ While the evidence to recommend use of SGAs

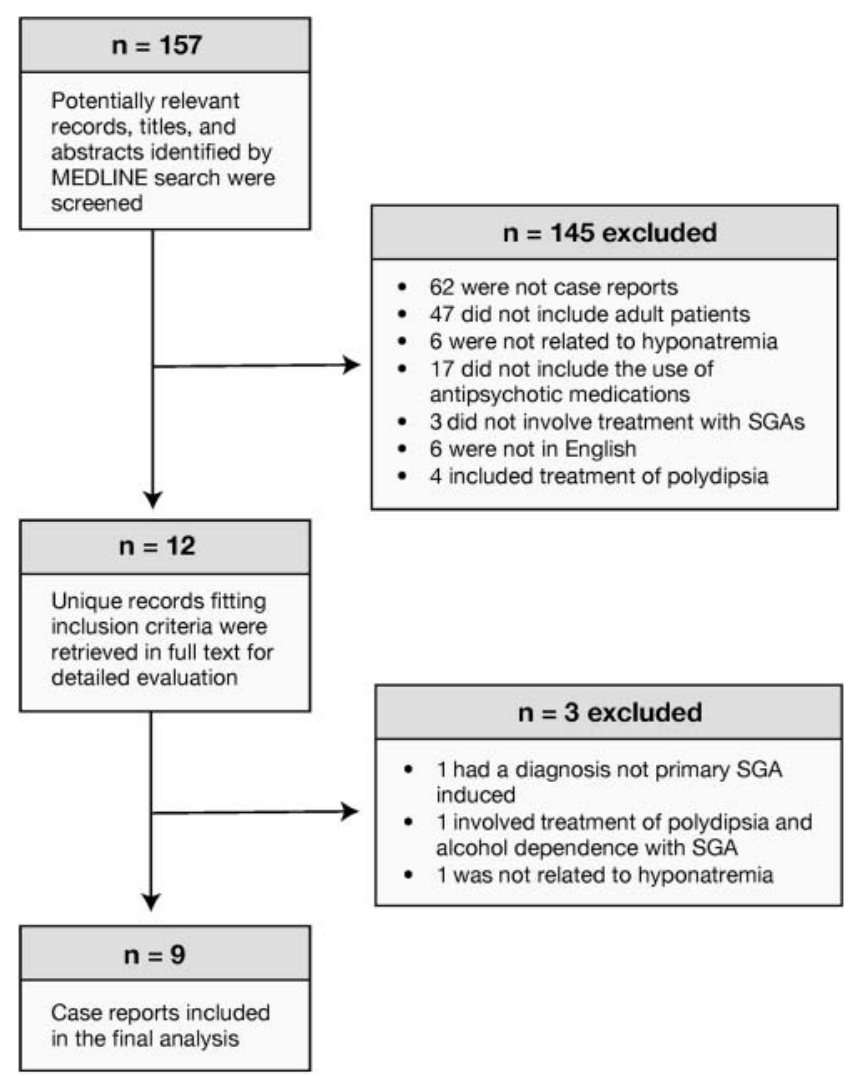

Figure. Flow diagram shows the number of articles identified and evaluated during the case report selection process. SGA, second-generation antipsychotic. over FGAs is insufficient, ${ }^{11}$ practice guidelines do not address the issue of monitoring for hyponatremia in patients with schizophrenia who are taking SGAs. ${ }^{12}$

While SGAs are the drugs of choice to treat schizophrenia because they are associated with fewer extrapyramidal symptoms, ${ }^{13}$ information available about the risk of hyponatremia associated with these medications is limited. ${ }^{4}$ In the cases of hyponatremia reported to be associated with SGAs, olanzapine (Zyprexa), risperidone (Risperdal), and clozapine (Clozaril) are most common. ${ }^{2}$ However, in most published reports, the drug dosage comparison and the risk association of concomitant interaction are not provided. . $^{2,3,9,14-24}$

A 2010 study examining the frequency of reporting hyponatremia with SGA medications in a drug safety database concluded that hyponatremia associated with SGA medications is likely to be underreported because of the concomitant use of other medications known to cause hyponatremia (eg, thiazide diuretics) and potential interaction. ${ }^{2}$

The purpose of this systematic review was to examine published cases reporting the use of SGAs and the occurrence of hyponatremia in patients with schizophrenia to inform physicians prescribing SGAs.

\section{METHODS \\ Search Strategy and Database}

We conducted a literature search of the MEDLINE database (from 1946 through September 2016) using the medical subject headings antipsychotic agents, hyponatremia, and water intoxication to identify cases reporting a diagnosis of hyponatremia after treatment with SGAs in patients with schizophrenia. The search was limited to articles in the English language.

\section{Inclusion and Exclusion Criteria}

Inclusion criteria were (1) a case report (2) describing hyponatremia (a serum sodium level $<135 \mathrm{mmol} / \mathrm{L}$ ) that (3) occurred after the start of treatment with one or more SGAs. ${ }^{1}$ Exclusion criteria were (1) serum sodium level was not 


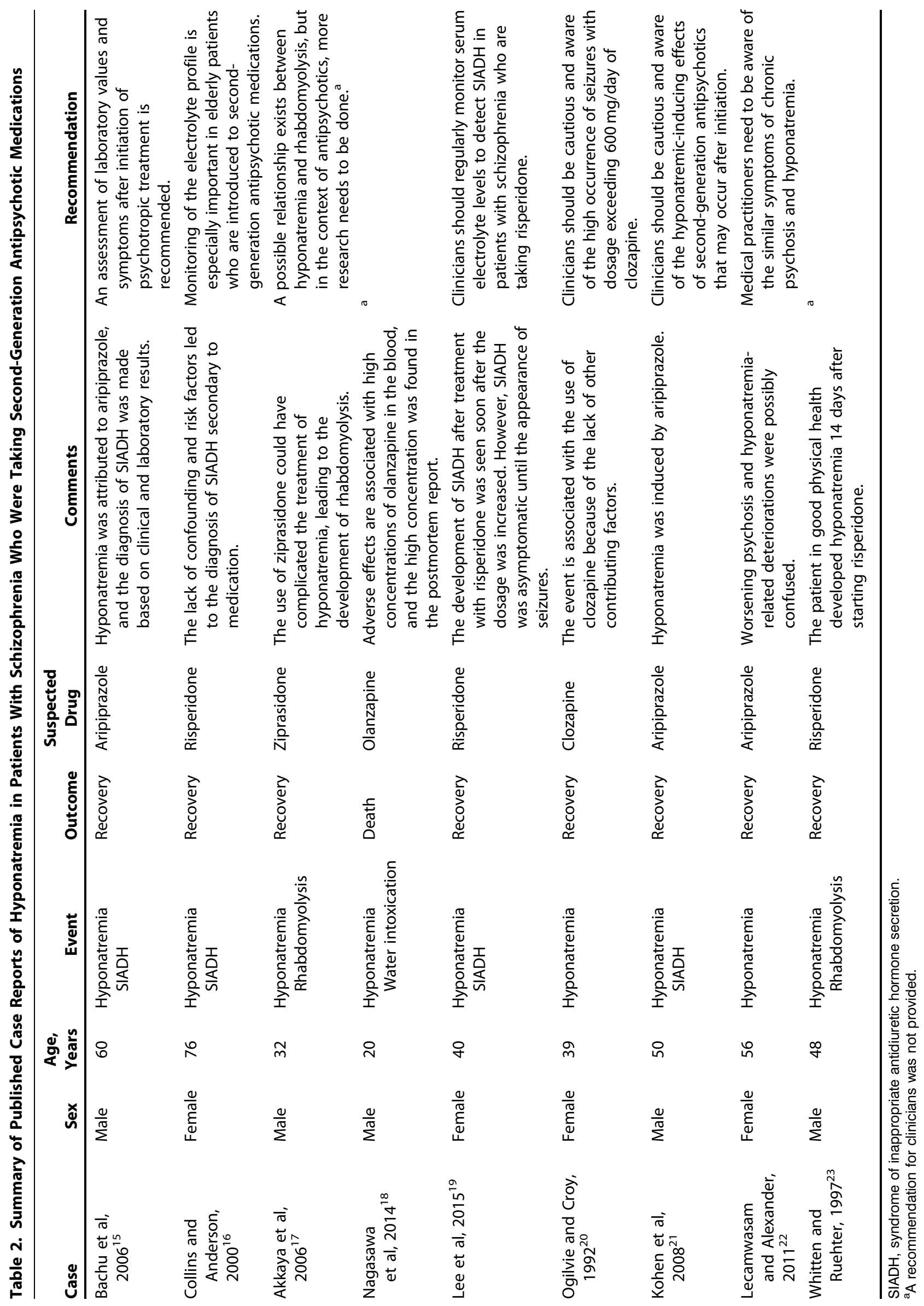


reported, (2) a clear diagnosis of schizophrenia was not documented, (3) an SGA was not administered, and (4) the subject of the report was not a human adult.

\section{Case Report Selection}

Our search yielded 157 unique titles that we screened by title and abstract to identify 12 pertinent case reports. These 12 potentially relevant cases were extracted in full text and evaluated in detail. Cases were excluded according to the previously described criteria. Nine case reports were selected for analysis, and data were abstracted. The Figure illustrates the selection process for the cases.

\section{RESULTS}

The 9 cases that met the inclusion criteria involved 5 male patients and 4 female patients with a mean age of 47 years. The patients' ages ranged from 20-76 years. ${ }^{15-23}$ Table 2 presents a summary of the cases with outcomes, author comments, and recommendations.

Four cases reported hyponatremia with the diagnosis of syndrome of inappropriate antidiuretic hormone secretion (SIADH), ${ }^{15,16,19,21} 2$ cases reported hyponatremia with rhabdomyolysis, ${ }^{17,23} 1$ case reported hyponatremia with the diagnosis of water intoxication, ${ }^{18}$ and 2 cases reported hyponatremia without another diagnosis. ${ }^{20,22}$

Three cases reported the use of risperidone (Risperdal), ${ }^{16,19,23} 3$ reported the use of aripiprazole (Abilify), ${ }^{15,21,22}$ and the remaining 3 cases reported the use of ziprasidone (Geodon), ${ }^{17}$ clozapine (Clozaril), ${ }^{20}$ and olanzapine (Zyprexa). ${ }^{18}$ Recovery from hyponatremia after discontinuation of SGA treatment was reported in 8 cases. The patient taking olanzapine died from hyponatremia/water intoxication that was likely associated with the use of the drug.

The patients' mean serum sodium level at baseline was $138 \mathrm{mmol} / \mathrm{L}$, with a mean drop to $112 \mathrm{mmol} / \mathrm{L}$ and a mean return to a normal serum sodium level of $138 \mathrm{mmol} / \mathrm{L}$ following the discontinuation of treatment. Table 3 presents the serum sodium levels by case. Table 4 reports recom- mended dosages, actual dosages used in the case scenarios, and the times to the hyponatremia event. All of these severe cases of hyponatremia occurred in patients who were dosed within the recommended SGA dosing ranges, except for the case involving olanzapine (Zyprexa). That patient was administered approximately 4 times the recommended maximum dose, and the result was death. ${ }^{15-23}$ The average time to the hyponatremia event for all cases was 17 days.

The authors of all 9 case reports proposed a link between the hyponatremia event and the use of SGAs based on the temporal relationship and the lack of an alternative explanation.

\section{DISCUSSION}

The cited cases involved 7 adults aged $20-56$ years and 2 elderly patients aged 60 and 76 years. The case report findings describing hyponatremia following SGA treatment represent a likely association; however, the absolute risk of this adverse event is currently unknown.

The inconsistency of the literature based on case reports alone demonstrates the need for studies with systematic assessments of adverse events such as hyponatremia occurring after the initiation of treatment with SGAs. While much of the literature implies greater susceptibility to hyponatremia in elderly patients ${ }^{25}$ who are also more vulnerable to adverse events following SGA treatment, our findings in the analyzed case reports did not clearly provide evidence of this phenomenon. The hypothesis that the elderly have a higher susceptibility to hyponatremia has significant biologic plausibility, as the underlying mechanisms that trigger thirst may deteriorate with age, weakening the ability to maintain water homeostasis in the body and increasing the risk for dehydration. ${ }^{26-28}$ Moreover, the well-known age-related decline in kidney function may also increase the risk for dehydration. ${ }^{26,28}$ The literature through 2016 reports an increased risk among females and the elderly for antipsychoticinduced hyponatremia. ${ }^{14,25,27,29}$ The expected decline in

Table 3. Patient Serum Sodium Measurements

\begin{tabular}{|c|c|c|c|c|}
\hline \multirow[b]{2}{*}{ Case } & \multirow{2}{*}{$\begin{array}{c}\text { Second-Generation } \\
\text { Antipsychotic } \\
\text { Medication }\end{array}$} & \multicolumn{3}{|c|}{ Serum Sodium, mmol/L } \\
\hline & & Baseline & $\begin{array}{l}\text { At Treatment } \\
\text { Nadir }\end{array}$ & $\begin{array}{l}\text { After Treatment } \\
\text { Discontinuation }\end{array}$ \\
\hline Bachu et al, $2006^{15}$ & Aripiprazole & $142^{\mathrm{a}}$ & $120^{\mathrm{a}}$ & $143^{a}$ \\
\hline Collins and Anderson, $2000^{16}$ & Risperidone & 134 & 116 & 134 \\
\hline Akkaya et al, $2006^{17}$ & Ziprasidone & $142^{\mathrm{a}}$ & $122^{\mathrm{a}}$ & $143^{\mathrm{a}}$ \\
\hline Nagasawa et al, $2014^{18}$ & Olanzapine & & $83^{a, b}$ & \\
\hline Lee et al, $2015^{19}$ & Risperidone & 136 & 106 & \\
\hline Ogilvie and Croy, $1992^{20}$ & Clozapine & & 113 & \\
\hline Kohen et al, $2008^{21}$ & Aripiprazole & 135 & 112 & 137 \\
\hline Lecamwasam and Alexander, $2011^{22}$ & Aripiprazole & & 124 & 136 \\
\hline \multirow[t]{3}{*}{ Whitten and Ruehter, $1997^{23}$} & Risperidone & & 110 & 136 \\
\hline & & \multicolumn{3}{|c|}{ Mean Serum Sodium, $\mathrm{mmol} / \mathrm{L}$} \\
\hline & & 138 & 112 & 138 \\
\hline
\end{tabular}

\footnotetext{
${ }^{a}$ Measurement was converted from $\mathrm{mEq} / \mathrm{L}$ to $\mathrm{mmol} / \mathrm{L}$ for data consistency.
}

${ }^{\mathrm{b}}$ Measurement was obtained from postmortem serum biochemistry. 
Table 4. Second-Generation Antipsychotic Recommended Doses, Dosages Reported, and Times to Hyponatremia Event

\begin{tabular}{|c|c|c|c|c|c|c|}
\hline \multirow[b]{2}{*}{ Case } & \multirow{2}{*}{$\begin{array}{c}\text { Second-Generation } \\
\text { Antipsychotic } \\
\text { Medication }\end{array}$} & \multicolumn{3}{|c|}{ Recommended Dosing $^{a}$} & \multirow{2}{*}{$\begin{array}{l}\text { Reported } \\
\text { Dosing, } \\
\text { mg/day }\end{array}$} & \multirow{2}{*}{$\begin{array}{c}\text { Time to } \\
\text { Event, } \\
\text { days }\end{array}$} \\
\hline & & $\begin{array}{l}\text { Initial, } \\
\text { mg/day }\end{array}$ & $\begin{array}{l}\text { Target, } \\
\text { mg/day }\end{array}$ & $\begin{array}{c}\text { Maximum, } \\
\text { mg/day }\end{array}$ & & \\
\hline Bachu et al, $2006^{15}$ & Aripiprazole & 50 & $400-800$ & 1,200 & $\begin{array}{l}10 \\
15 \\
20\end{array}$ & 4 \\
\hline Collins and Anderson, $2000^{16}$ & Risperidone & 2 & $4-8$ & 16 & 0.5 & 14 \\
\hline Akkaya et al, $2006^{17}$ & Ziprasidone & 80 & $40-160$ & 160 & $\begin{array}{c}80 \\
120\end{array}$ & 21 \\
\hline Nagasawa et al, $2014^{18}$ & Olanzapine & 1 & $2-4$ & 4 & 15 & $\mathrm{~b}$ \\
\hline Lee et al, $2015^{19}$ & Risperidone & 2 & $4-8$ & 16 & $\begin{array}{c}4 \\
12\end{array}$ & 14 \\
\hline Ogilvie and Croy, $1992^{20}$ & Clozapine & 12.5 & $300-450$ & 900 & 300 & 49 \\
\hline Kohen et al, $2008^{21}$ & Aripiprazole & $10-15$ & $10-15$ & 30 & $\begin{array}{l}15 \\
20\end{array}$ & 3 \\
\hline Lecamwasam and Alexander, $2011^{22}$ & Aripiprazole & $10-15$ & $10-15$ & 30 & 30 & $>5^{c}$ \\
\hline Whitten and Ruehter, $1997^{23}$ & Risperidone & 2 & $4-8$ & 16 & $\begin{array}{l}2 \\
6\end{array}$ & 14 \\
\hline
\end{tabular}

\footnotetext{
${ }^{\mathrm{a}}$ Recommended dosage for schizophrenia indication obtained from the corresponding Full Prescribing Information Guide.

${ }^{\mathrm{b}}$ Time to event was not provided in the report.

'Exact value is unknown; therefore, the value was not included in the calculation of the mean time to event reported in the text.
}

renal function in the elderly may explain this phenomenon. The increased risk among females may be confounded by body size, as low body weight has been identified as a risk factor. ${ }^{25,29}$ Low body weight may also explain the increased risk in the elderly. ${ }^{25}$ These factors may contribute to the incidence of hyponatremia, but evidence is sparse. $^{14,25,29,30}$

From examination of the literature and our results, higher dosage treatment regimens with SGAs appear to be related to adverse effects. Regardless of the underlying cause, hyponatremia is associated with a risk of death. ${ }^{2,6,23}$ The electrolyte imbalance is likely to increase morbidity and mortality if left untreated. ${ }^{10,30-33}$ In addition, distinguishing the symptoms and signs of schizophrenia from hyponatremia-related neurologic deterioration may be difficult. ${ }^{3,9}$ Our findings suggest the importance of monitoring this electrolyte disorder closely within the first 2 weeks of SGA treatment initiation (given our average time to event of 17 days) and the importance of following proper dosing information within the first 3 days of treatment (our minimum time to event was 3 days).

In clinical practice, the SGAs commonly prescribed to treat patients with schizophrenia differ in drug composition and safety profile; however, commonly prescribed SGAs and those included in this review (clozapine, risperidone, aripiprazole, ziprasidone, and olanzapine) block cerebral dopamine pathways to treat the symptoms of patients.

\section{CONCLUSION}

Because hyponatremia is life-threatening in severe cases but is preventable in most cases with the discontinuation of SGA treatment, monitoring electrolyte levels during treatment with SGAs is important. Serum sodium levels returned to normal following the discontinuation of treatment in almost all the cases in our review. Increasing the awareness among psychiatric providers of this potential serious adverse event associated with SGAs is critical because of the prevalence of these medications in treating vulnerable patients with schizophrenia.

\section{ACKNOWLEDGMENTS}

The authors have no financial or proprietary interest in the subject matter of this article.

\section{REFERENCES}

1. Meyer JS, Quenzer LF. Psychopharmacology: Drugs, the Brain, and Behavior. 2nd ed. Sunderland, MA: Sinauer Associates; 2013.

2. Mannesse CK, van Puijenbroek EP, Jansen PA, van Marum RJ, Souverein PC, Egberts TC. Hyponatraemia as an adverse drug reaction of antipsychotic drugs: a case-control study in VigiBase. Drug Saf. 2010 Jul 1;33(7):569-578. doi: 10.2165/ 11532560-000000000-00000.

3. Meulendijks D, Mannesse CK, Jansen PA, van Marum RJ, Egberts TC. Antipsychotic-induced hyponatraemia: a systematic review of the published evidence. Drug Saf. 2010 Feb 1;33(2):101-114. doi: 10.2165/11319070-000000000-00000.

4. Yang HJ, Cheng WJ. Antipsychotic use is a risk factor for hyponatremia in patients with schizophrenia: a 15-year followup study. Psychopharmacology (Berl). 2017 Mar;234(5):869-876. doi: 10.1007/s00213-017-4525-4529.

5. Spasovski G, Vanholder R, Allolio B, et al; Hyponatraemia Guideline Development Group. Clinical practice guideline on diagnosis and treatment of hyponatraemia. Eur J Endocrinol. 2014 Feb 25;170(3):G1-G47. doi: 10.1530/EJE-13-1020.

6. Adrogué HJ, Madias NE. Hypernatremia. N Engl J Med. 2000 May 18;342(20):1493-1499.

7. Siegel AJ. Hyponatremia in psychiatric patients: update on evaluation and management. Harv Rev Psychiatry. 2008;16 (1):13-24. doi: 10.1080/10673220801924308. 
8. Lange-Asschenfeldt C, Kojda G, Cordes J, et al. Epidemiology, symptoms, and treatment characteristics of hyponatremic psychiatric inpatients. J Clin Psychopharmacol. 2013 Dec;33 (6):799-805. doi: 10.1097/JCP.0b013e3182a4736f.

9. Spigset $\mathrm{O}$, Hedenmalm K. Hyponatraemia and the syndrome of inappropriate antidiuretic hormone secretion (SIADH) induced by psychotropic drugs. Drug Saf. 1995 Mar;12(3): 209-225.

10. Abou-Setta AM, Mousavi SS, Spooner C, et al. First-Generation Versus Second-Generation Antipsychotics in Adults: Comparative Effectiveness. Rockville (MD): Agency for Healthcare Research and Quality (US); 2012 Aug. http://www.ncbi.nlm.nih.gov /books/NBK107254/. Accessed November 21, 2017.

11. Buchanan RW, Kreyenbuhl J, Kelly DL, et al; Schizophrenia Patient Outcomes Research Team (PORT). The 2009 schizophrenia PORT psychopharmacological treatment recommendations and summary statements. Schizophr Bull. 2010 Jan;36(1):71-93.

12. Lehman AF, Lieberman JA, Dixon LB, et al; American Psychiatric Association; Steering Committee on Practice Guidelines. Practice guideline for the treatment of patients with schizophrenia, second edition. Am J Psychiatry. 2004 Feb;161(2 Suppl):1-56.

13. Patel KR, Cherian J, Gohil K, Atkinson D. Schizophrenia: overview and treatment options. P T. 2014 Sep;39(9):638-645.

14. Atalay A, Turhan N, Aki OE. A challenging case of syndrome of inappropriate secretion of antidiuretic hormone in an elderly patient secondary to quetiapine. South Med J. 2007 Aug;100 (8):832-833.

15. Bachu K, Godkar D, Gasparyan A, Sircar P, Yakoby M, Niranjan S. Aripiprazole-induced syndrome of inappropriate antidiuretic hormone secretion (SIADH). Am J Ther. 2006 Jul-Aug;13(4):370372.

16. Collins A, Anderson J. SIADH induced by two atypical antipsychotics. Int J Geriatr Psychiatry. 2000 Mar;15(3):282-3. Erratum in: Int J Geriatr Psychiatry. 2000 Jul;15(7):667.

17. Akkaya C, Sarandol A, Sivrioglu EY, Kotan Z, Kirli S. A patient using ziprasidone with polydipsia, seizure, hyponatremia and rhabdomyolysis. Prog Neuropsychopharmacol Biol Psychiatry. 2006 Dec 30;30(8):1535-1538.

18. Nagasawa S, Yajima D, Torimitsu S, Abe H, Iwase H. Fatal water intoxication during olanzapine treatment: a case report. Leg Med (Tokyo). 2014 Mar;16(2):89-91. doi: 10.1016/j. legalmed.2013.12.003.
19. Lee YF, Tsai CK, Liang CS. High-dose risperidone induced latent syndrome of inappropriate antidiuretic hormone secretion with seizure presentation. Clin Neuropharmacol. 2015 JulAug;38(4):154-155. doi: 10.1097/WNF.0000000000000095.

20. Ogilvie $A D$, Croy MF. Clozapine and hyponatraemia. Lancet. 1992 Sep 12;340(8820):672.

21. Kohen I, Voelker S, Manu P. Antipsychotic-induced hyponatremia: case report and literature review. Am J Ther. 2008 Sep-Oct;15(5):492-494. doi: 10.1097/MJT. 0b013e31817276e9.

22. Lecamwasam DL, Alexander J. Aripiprazole associated hyponatraemia. Aust N Z J Psychiatry. 2011 Aug;45(8):686-687. doi: 10.3109/00048674.2011.580453.

23. Whitten JR, Ruehter VL. Risperidone and hyponatremia: a case report. Ann Clin Psychiatry. 1997 Sep;9(3):181-183.

24. Gandhi S, McArthur E, Reiss JP, et al. Atypical antipsychotic medications and hyponatremia in older adults: a populationbased cohort study. Can J Kidney Health Dis. 2016 Apr 11;3:21. doi: 10.1186/s40697-016-0111-z.

25. Upadhyay A, Jaber BL, Madias NE. Incidence and prevalence of hyponatremia. Am J Med. 2006 Jul;119(7 Suppl 1):S30-5.

26. Rowe JW, Shock NW, DeFronzo RA. The influence of age on the renal response to water deprivation in man. Nephron. 1976;17 (4):270-278.

27. Hawkins RC. Age and gender as risk factors for hyponatremia and hypernatremia. Clin Chim Acta. 2003 Nov;337(1-2):169-172.

28. Kugler JP, Hustead T. Hyponatremia and hypernatremia in the elderly. Am Fam Physician. 2000 Jun 15;61(12):3623-3630.

29. Madhusoodanan S, Bogunovic OJ, Moise D, Brenner R, Markowitz S, Sotelo J. Hyponatraemia associated with psychotropic medications: a review of the literature and spontaneous reports. Adverse Drug React Toxicol Rev. 2002; 21(1-2):17-29.

30. Bhuvaneswar CG, Baldessarini RJ, Harsh VL, Alpert JE. Adverse endocrine and metabolic effects of psychotropic drugs: selective clinical review. CNS Drugs. 2009 Dec;23(12):1003-1021. doi: 10.2165/11530020-000000000-00000.

31. Tierney WM, Martin DK, Greenlee MC, Zerbe RL, McDonald CJ. The prognosis of hyponatremia at hospital admission. $J$ Gen Intern Med. 1986 Nov-Dec;1(6):380-385.

32. Baran D, Hutchinson TA. The outcome of hyponatremia in a general hospital population. Clin Nephrol. 1984 Aug;22(2):72-76.

33. Bhatnagar $D$, Weinkove $C$. Serious hypernatraemia in a hospital population. Postgrad Med J. 1988 Jun;64(752):441-443.

This article meets the Accreditation Council for Graduate Medical Education and the American Board of Medical Specialties Maintenance of Certification competencies for Patient Care, Medical Knowledge, and Practice-Based Learning and Improvement. 